\title{
NEOLIBERALISMO E REFORMA TRABALHISTA
}

\author{
José Dari Krein
}

O tema da reforma sindical e trabalhista está na agenda brasileira desde o processo de redemocratização, com o surgimento do "novo sindicalismo", mas com significados distintos em cada momento histórico, dependendo dos interesses em jogo e da correlação de forças entre os agentes sociais. Apesar das transformações ocorridas, elementos centrais da estrutura sindical herdada nos anos 1930-1940 permanecem em vigor, especialmente a unicidade sindical e as contribuições sindicais compulsórias. Essa premissa significa assumir uma posição no debate acadêmico, pois alguns autores consideram que esses aspectos são apenas formais, de modo que não caberia mais falar em corporativismo. A unicidade já não vigoraria na prática, de modo que preferem falar em modelo legislado-pluralista (CARDOSO, 1997; 2001; NORONHA, 1999). Mas a questão fica mais embaralhada a partir dos anos 1990, pois certas bandeiras são apropriadas pelos neoliberais e a elas é dado um novo significado, tais como a defesa da liberdade e da autonomia sindicais e da valorização da contratação coletiva. Além disso, especialmente após 1994, a ênfase da reforma é dada à questão trabalhista, sob a hegemonia de um discurso liberalizante e conservador, em que ela é traduzida na proposta de flexibilização dos direitos como condição para superar os problemas existentes no mercado de trabalho brasileiro.

Essa é a temática do livro de Andréia Galvão, Neoliberalismo e reforma trabalhista no Brasil ${ }^{1}$, constituindo-se em uma referência para quem quer compreender a evolução do debate sobre o tema, bem como as mudanças na regulação do trabalho e as estratégias adotadas pelos agentes sociais. Independentemente da concordância ou não com as posições adotadas pela autora, é uma referência por apresentar um texto bem fundamentado, com consistência teórica e com uma ampla base empírica (documentos, resoluções, intervenções em debates públicos e na imprensa etc.). Contém um excepcional levantamento de informações e de posições acadêmicas dos agentes sociais sobre todas as iniciativas e debates englobando o tema da reforma sindical e trabalhista entre 1990 e 2002, especialmente em relação às alterações da estrutura sindical, da normatização da relação de emprego e do papel do Estado na sociedade e na regulação do trabalho. Apesar de a pesquisa ir até 2002, é um estudo que traz muitos elementos para compreender as dificuldades para a realização de uma reforma da estrutura sindical no Brasil, contribuindo para entender as razões que levaram à fracassada iniciativa de o Fórum Nacional do Trabalho, no governo Lula, de viabilizar uma reforma sindical no Brasil. Aliás, uma das questões que a autora propõe-se a discutir é exatamente as razões que deixaram a reforma sindical em segundo plano.

Além da quantidade e do rigor das informações que ajudam a compreender a evolução das iniciativas, o livro traz como contribuição à reflexão uma análise dos diferentes interesses e orientações dos principais agentes sociais (de empregadores e trabalhadores) em cada conjuntura concreta, evidenciando a complexidade de um “processo constituído de múltiplos pólos aglutinadores” (BOITO JR., 2007, p. 17.). Nesse sentido, evidencia como o posicionamento dos agentes foi alterando-se nos movimentos conjunturais, em função das correlações de força. O texto mostra, ainda, como o neoliberalismo influencia não só o mundo do trabalho (desemprego, precarização, perda de direitos, adversidades à ação coletiva, mobilizações), mas também o posicionamento das entidades de representação dos trabalhadores.

Uma das principais teses do livro é que a conformação da regulação do trabalho e as mudanças no discurso e/ou na prática dos agentes sociais têm relação com os projetos (inclusive sindical) em disputa na sociedade, dada pela correlação de força entre capital e trabalho e entre frações de classe. Assim, no primeiro plano, a autora explica, especialmente quando se consolida a hegemonia neoliberal, uma agenda mais conservadora na discussão da reforma trabalhista, deixando em segundo plano a questão da reforma sindical. Ou seja, a agenda

\footnotetext{
1 O livro é uma versão revisada de sua tese de doutoramento, defendida em 2003, no Instituto de Filosofia e Ciências Humanas da Universidade Estadual de Campinas (Unicamp).
} 
da flexibilização ${ }^{2}$ das relações de trabalho, a partir do Plano Real (1994), pautará as principais iniciativas no campo legislativo e mesmo na normatização autônoma entre capital e trabalho, por meio das negociações coletivas. "[...] A reforma trabalhista não constitui uma demanda nova, nem é prerrogativa dos neoliberais: a definição dos contornos da reforma trabalhista varia conforme o agente social considerado o contexto em questão” (GALVÃO, 2007, p. 101).

Assim, a partir principalmente de Boito Jr. (1999) e Saes (2001), a autora destaca que a consolidação do liberalismo não é meramente fruto do poder do dinheiro e da mídia, mas constitui-se como um projeto que foi impulsionado pela burguesia - com destacado papel da indústria paulista na sua consagração - e encontra respaldo junto a uma parcela de trabalhadores e de organizações sindicais. Por exemplo, o discurso da privatização e da reforma do Estado encontra respaldo em parte da sociedade, dada a baixa qualidade do serviço público, assim como a visão de que a flexibilização - que significa reduzir o custo do trabalho eliminando direitos e proteção social - pode contribuir para a geração de ocupações e acabar com "privilégios" existentes nos setores mais organizados, especialmente nas estatais e no serviço público. Esse ponto de vista é respaldado academicamente por Pastore (1994), que, utilizando como referência Reginaldo Moraes (2001), compreende o neoliberalismo como uma ideologia e um conjunto de políticas que tendem a fragilizar o Estado e a fortalecer o mercado como instrumento de organização da vida em sociedade. Mas é curioso notar que o discurso do "Estado mínimo" não é praticado em relação à imposição das reformas liberalizantes e nem para reprimir os movimentos de contestação. Muitas das reformas só se viabilizaram pelo poder dessa instituição chamada "Estado". Portanto, a ideologia neoliberal, ao convencer e atrair parte dos trabalhadores, contribui também para neutralizar as ações de resistências, apesar da existência destas, como é indicado no livro. Essa análise sobre o neoliberalismo, que constitui o tema do capítulo 1, assim como em toda a referência teórica do livro, está respaldada em uma vasta bibliografia de autores de tradição marxista.

Como destacado acima, ao mesmo tempo a autora analisa como o neoliberalismo influencia as estratégias dos diferentes agentes sociais. Por exemplo, “[...] há uma disputa permanente pelo significado e pelo alcance da lei do contrato. A lei é vista ora como espaço de resistência, ora como instrumento de controle; o contrato, como reino da liberdade e como fonte de prejuízo. Como sugerimos anteriormente, a luta de classes faz com que as classes em disputa se apoderem dos discursos de oponentes, atribuindo-lhe novos conteúdos em conjunturas distintas” (GALVÃO, 2007, p. 196).

Ao falar em conjunturas distintas, a autora destaca dois períodos distintos, antes e depois do Plano Real. No capítulo 2, analisa as iniciativas e os projetos de mudanças discutidos entre 1990 e 1995, quando houve um amplo debate com a criação de fóruns e a elaboração de propostas por parte de diferentes agentes sociais, especialmente no momento da constituição do Fórum Nacional de Relações de Trabalho e Contrato Coletivo de Trabalho e discute as razões de por que mesmo projetos tímidos - pois, na sua avaliação, não colocavam em questão o cerne da estrutura corporativista que é a unicidade sindical - não apresentam efetividade. Em síntese, destaca duas razões principais para isso:

1) em primeiro lugar, apesar de um aparente (e falso) consenso sobre a necessidade de realizar uma reforma sindical e trabalhista, as posições dos agentes apresentavam grandes diferenças de projetos entre si. No campo social do trabalho, somente a Central Geral dos Trabalhadores (CGT), das instituições analisadas, tinha uma clara posição pela manutenção do sistema corporativo. As duas outras centrais (Central Única dos Trabalhadores (CUT) e Força Sindical (FS)) tinham uma posição de defesa da liberdade e da autonomia sindicais e do fim das contribuições compulsórias. Mas a autora procura evidenciar as contradições (1) no próprio discurso - especialmente na discussão das propostas apresentadas pelos governantes - em diferentes conjunturas e (2) entre a prática e o discurso, em que táticas equivocadas acabam fortalecendo a estrutura oficial. Além disso, destaca a falta de consenso no interior das centrais,

\footnotetext{
$\overline{2}$ Em concordância com a autora, pode-se verificar que houve mais uma agenda de flexibilização do que de desregulamentação, pois a análise do conjunto das iniciativas mostra que foi a introduzido uma série de medidas que amplia o caráter flexível da relação de emprego no Brasil, tais como o Programa de Participação nos Lucros e Resultados (PLR), o banco de horas, novas formas de contratação, comissões de conciliação prévias etc. É mais e não menos lei. O problema é o conteúdo dessa legislação. É verdade que houve supressão de direitos, especialmente na reforma da Previdência Social e na reforma administrativa (para servidores públicos). Mas também é um fato que, apesar da extensa legislação, nunca constituímos no país uma regulação pública do trabalho (KREIN, 2007).
} 
especialmente na CUT, que tem tendências internas constituídas. Assim, o leitor encontra uma análise crítica sobre a CUT, especialmente direcionada para a sua corrente majoritária;

2) em segundo lugar, há uma progressiva acomodação e resignação dos líderes dos trabalhadores à estrutura oficial.

No campo do capital, as posições são hesitantes e também contraditórias em relação à reforma da estrutura sindical. O discurso da liberdade sindical e do fim das contribuições é defendido somente por algumas lideranças da Federação das Indústrias do Estado de São Paulo (Fiesp), especialmente dos setores mais estruturados economicamente. Mas não há registro nem de pressão sistemática nem de apresentação de um projeto de reforma sindical. O que há de consensual no setor patronal é a necessidade de uma reforma em que prevaleça o negociado sobre o legislado, de flexibilização dos direitos trabalhistas, de posição contra qualquer “engessamento das normas de proteção ao trabalho" (idem, p. 174). Assim, a reforma pretendida é a trabalhista, em que a relação de emprego possa ser adaptada à lógica de competitividade das empresas.

A partir do Plano Real torna-se hegemônica essa visão empresarial. No capítulo 3, há uma descrição e uma análise das principais medidas adotadas pelo governo Fernando Henrique Cardoso, que ocorreram com a perspectiva de promover uma flexibilização das relações de trabalho, de reduzir a proteção social e de redefinir o papel do Estado na regulação do trabalho. É o período de consolidação do neoliberalismo no Brasil. A análise, como dito anteriormente, compreende o posicionamento dos agentes sociais, em que predominam novamente movimentos ambíguos. No campo social do trabalho, destaca a posição histórica da Força Sindical pelo seu pragmatismo, em geral apoiando reformas de flexibilização, mas às vezes desenvolvendo ações conjuntas com outras centrais contra o desemprego ou contra a substituição do tempo de serviço pelo de contribuição na reforma da Previdência Social. Em relação à CUT, a autora destaca as suas ambigüidades: por um lado, por exemplo, reconhece as iniciativas de resistência ao neoliberalismo, empreendidas no período; por outro lado, na sua visão, uma estratégia de ação propositiva no final a conduz a uma posição que privilegia a negociação institucional em detrimento das mobilizações na base. Também leva a uma redução do escopo das demandas "realistas" para aquilo que é possível ser negociado no âmbito permitido pelo contexto (ou seja, no marco aceitável pelo capital). Isso levou a CUT a aceitar, na opinião da autora, algumas medidas flexibilizadoras, apesar de manter um discurso crítico à flexibilização.

No capítulo 4, a autora enumera e discute as propostas em debate entre 1995 e 2002 na estrutura sindical, mostrando que o ímpeto pela reforma foi perdendo espaço entre os agentes sociais. Ao explicar a perenidade da estrutura oficial, Galvão destaca os seguintes fatores. Em primeiro lugar, o setor empresarial não demonstra interesse em reformar essa estrutura. Em segundo lugar, cresce a resistência contra a reforma, materializada na contraposição às propostas apresentadas pelo governo (reforma sindical de 1998 (Proposta de Emenda Constitucional n. 623) e a prevalência do negociado sobre o legislado). Com isso ganha força o argumento de que a estrutura oficial atende a "interesses materiais dos sindicatos" ao garantir condições de sua sobrevivência (idem, p. 327), em um contexto de ataque aos direitos e à organização coletiva dos trabalhadores. Assim, a autora identifica, mesmo nos grupos mais à esquerda, a prevalência de uma posição contrária a qualquer reforma, sob a justificativa de que o contexto econômico e político é desfavorável aos trabalhadores. Como o movimento sindical não apresenta nenhuma proposta de reforma fica em uma posição defensiva contra a ofensiva do governo de desarticular os direitos e as instituições públicas na área do trabalho. Portanto, cresce uma posição de defesa das salvaguardas garantidas pela estrutura atual, pois ao menos ela garante o funcionamento do sindicato. A autora também deixa entender que os trabalhadores não perceberam que a estrutura oficial pode cumprir um importante papel na dominação de classe, o que dificulta qualquer mudança. Diríamos que a autora também destaca o papel que a estrutura oficial desempenha na dominação de classe, contribuindo para a flexibilização das relações de trabalho na medida em que possibilita a sobrevivência de lideranças comprometidas com o capital e favoráveis ao seu projeto de reforma trabalhista.

Nesse sentido, a autora manifesta claramente no livro sua posição favorável à liberdade sindical, inclusive debatendo com quem defende a unicidade. Como bem destaca Armando Boito Jr., no “Prefácio”, a obra traz a boa polêmica sem fazer “concessão à diplomacia acadêmica” (BOITO JR., 2007, p. 17). O leitor encontrará um texto posicionado e bem fundamentado, herdeira de uma literatura crítica à estrutura sindical corporativa, especialmente do princípio da unicidade sindical, buscando em todo momento verificar o jogo de interesses e os projetos em disputa pelos diferentes agentes sociais. 
Mas algumas questões suscitadas no livro continuam em debate. Apesar da importante contribuição da autora, a discussão as resistências a reformas profundas na estrutura sindical ainda consumirá muita tinta, especialmente com a progressiva perda de adeptos, em todas as correntes sindicais, da defesa de sua reformulação. O dissenso a respeito do caráter da reforma parece aprofundar-se. Por exemplo, como garantir a sustentação financeira das entidades sindicais em um mercado de trabalho segmentado e heterogêneo, especialmente em setores mais frágeis economicamente? Quais as possibilidades de organização sindical em um país continental e com uma classe trabalhadora absolutamente heterogênea, em que se aprofunda a fragmentação e deixa de fora da base de representação das atuais instituições sindicais a maioria dos trabalhadores? Na mesma direção, qual o papel do Estado na regulação do trabalho, dadas as especificidades do mercado de trabalho brasileiro? Também há a necessidade de continuar a análise sobre o significado das diferentes estratégias sindicais no período do neoliberalismo, assim como não se apresenta como questão a análise das experiências de organização fora da estrutura sindical oficial. Enfim, está em aberto o debate sobre a natureza da crise do sindicalismo brasileiro a partir dos anos 1990, como parte de uma crise mais geral da esquerda e das formas clássicas de organização. Talvez não seja apenas uma questão ideológica, pois a fragilização e a perda de capacidade de mobilização é um fenômeno generalizado, inclusive nos agrupamentos considerados mais à esquerda do sindicalismo.

Por último, mais importante que concordar com as posições é reconhecer o mérito do trabalho acadêmico, que o livro tem de sobra.

José Dari Krein (dari@eco.unicamp.br) é Doutor em Economia Social e do Trabalho pela Universidade Estadual de Campinas (Unicamp) e professor do Instituto de Economia da mesma instituição.

\section{REFERÊNCIASBIBLIOGRÁFICAS}

BOITO JR., A. 1999. Política neoliberal e sindicalismo no Brasil. São Paulo : Xamã.

2007. Prefácio. In : GALVÃO, A. Neoliberalismo e reforma trabalhista no Brasil. Rio de Janeiro : Revan.

CARDOSO, A. 1997. O sindicalismo corporativo não é mais o mesmo. Novos Estudos, São Paulo, n. 48, p. 97119 , jul.

2001. Direito do trabalho e relações de classe no Brasil contemporâneo. Artigo apresentado no XXV Encontro Anual da Associação Nacional de Pós-Graduação e Pesquisa em Ciências Sociais, realizado entre 16 e 20 de outubro, em Caxambu (Minas Gerais). Digit.

KREIN, J. D. 2007. As tendências recentes na relação de emprego no Brasil : 1990-2005. Campinas. Tese (Doutorado em Economia Social e do Trabalho). Universidade Estadual de Campinas.

MORAES, R. 2001. Neoliberalismo : de onde vem, para onde vai ? São Paulo : SENAC.

NORONHA, E. 1999. Entre a lei e a arbitrariedade : mercados e relações de trabalho no Brasil. São Paulo : LTr.

PASTORE, J. 1994. A flexibilidade do trabalho. São Paulo : LTr.

SAES, D. 2001. República do capital. São Paulo : Boitempo. 